\title{
On the Efficacy of Compact Radar Transponders for InSAR Geodesy: Results of Multi-year Field Tests
}

\author{
Richard Czikhardt, Hans van der Marel, Juraj Papco and Ramon F. Hanssen, Senior Member, IEEE
}

\begin{abstract}
Compact and low-cost radar transponders are an attractive alternative to corner reflectors (CR) for SAR interferometric (InSAR) deformation monitoring, datum connection, and geodetic data integration. Recently, such transponders have become commercially available for $\mathrm{C}$-band sensors, which poses relevant questions on their characteristics in terms of radiometric, geometric, and phase stability. Especially for extended time series and for high-precision geodetic applications, the impact of secular or seasonal effects, such as variations in temperature and humidity, has yet to be proven. Here we address these challenges using a multitude of short baseline experiments with four transponders and six corner reflectors deployed at test sites in the Netherlands and Slovakia. Combined together, we analyzed 980 transponder measurements in Sentinel-1 time series to a maximum extent of 21 months. We find an average Radar Cross Section (RCS) of over $42 \mathrm{dBm}^{2}$ within a range of up to 15 degrees of elevation misalignment, which is comparable to a triangular trihedral corner reflector with a leg length of $2.0 \mathrm{~m}$. Its RCS shows temporal variations of $0.3-0.7 \mathrm{dBm}^{2}$ (standard deviation) which is partially correlated with surface temperature changes. The precision of the InSAR phase doubledifferences over short baselines between a transponder and a stable reference corner reflectors is found to be $0.5-1.2 \mathrm{~mm}$ (one sigma). We observe a correlation with surface temperature, leading to seasonal variations of up to $\pm 3 \mathrm{~mm}$, which should be modeled and corrected for in high precision InSAR applications. For precise SAR positioning, we observe antenna-specific constant internal electronic delays of $1.2-2.1 \mathrm{~m}$ in slant-range, i.e., within the range resolution of the Sentinel-1 Interferometric Wide Swath (IW) product, with a temporal variability of less than $20 \mathrm{~cm}$. Comparing similar transponders from the same series, we observe distinct differences in performance. Our main conclusion is that these characteristics are favorable for a wide range of geodetic applications. For particular demanding applications, individual calibration of single devices is strongly recommended.
\end{abstract}

\section{INTRODUCTION}

$\mathbf{R}$ ADAR transponders are active electronic devices that receive a radar signal, amplify it, and transmit it back to its source, such as a satellite carrying a Synthetic Aperture Radar (SAR) antenna. They can serve as a compact alternative to corner reflectors (CR) for precise SAR positioning [1], [2], SAR interferometry (InSAR), deformation monitoring over

R. Czikhardt and J. Papco are with the Department of Theoretical Geodesy and Geoinformatics, Slovak University of Technology, Radlinskeho 11, 810 05 Bratislava, Slovakia, e-mail: richard.czikhardt@stuba.sk.

H. van der Marel and R. F. Hanssen are with the Department of Geoscience and Remote Sensing, Delft University of Technology, 2628 CN Delft, The Netherlands.

This is a non-peer reviewed preprint version submitted for publication in IEEE Transactions on Geoscience and Remote Sensing. areas with few natural coherent scatterers [3], InSAR datum connection, and geodetic data integration to provide an absolute reference to the inherently relative InSAR measurements [4].

Recently, medium to low cost transponders for such applications have entered the market for C-band SAR sensors, which triggers questions about their performance and applicability for specific studies. In particular, this concerns their precise radiometric and geometric characteristics, InSAR phase stability, and dependence of external secular or seasonal effects, such as variations in temperature and humidity. Especially for longterm geodetic applications, or as permanent reference stations, there is a need for performance metrics. The aim of this study is to derive these quantitative quality metrics based on multiyear experiments with transponders.

\section{RADAR TRANSPONDERS}

We used C-band transponders manufactured by [5], locally referred to as electronic corner reflectors (ECR), see Fig. 1. Measuring $360 \times 570 \times 233 \mathrm{~mm}$, they contain two pairs of transmit and receive antennas, for the ascending and descending orbits of right-looking satellites, such as Sentinel-1 and Radarsat-2. The distance between the receive and transmit antennas is $450 \mathrm{~mm}$ to avoid interference. The transponder receives the C-band signal via a squinted receive 'patch' antenna, amplifies it, and transmits it back to the source using equally oriented transmit 'patch' antenna. It operates at a bandwidth of $5.405 \mathrm{GHz} \pm 100 \mathrm{MHz}$. The antennas are placed under the protective plastic dome, see Fig. 1(a), transparent to C-band signals. Their orientation can be optimized for the average line-of-sight direction at the latitude at which they are deployed. For European latitudes, they are squinted in azimuth by $12^{\circ}$ (southward from the east-west direction) and tilted in elevation by $32^{\circ}$ with respect to the zenith. The azimuth and elevation beamwidths are $20^{\circ}$ and $40^{\circ}$, respectively, enabling an orientation to the average Sentinel-1 incidence and zeroDoppler angles for overlapping tracks, while allowing for slight misalignment. The transponder can be configured to receive and transmit in either vertical or horizontal linear polarization, and is switched on automatically based on the selected satellite overpass times. The main function of the integrated GNSS receiver, with 22 tracking channels, is to keep the internal oscillator of the microcontroller synchronized with respect to the time reference (UTC). The time of synchronisation can be programmed on a regular basis, e.g. every 12 hours. 


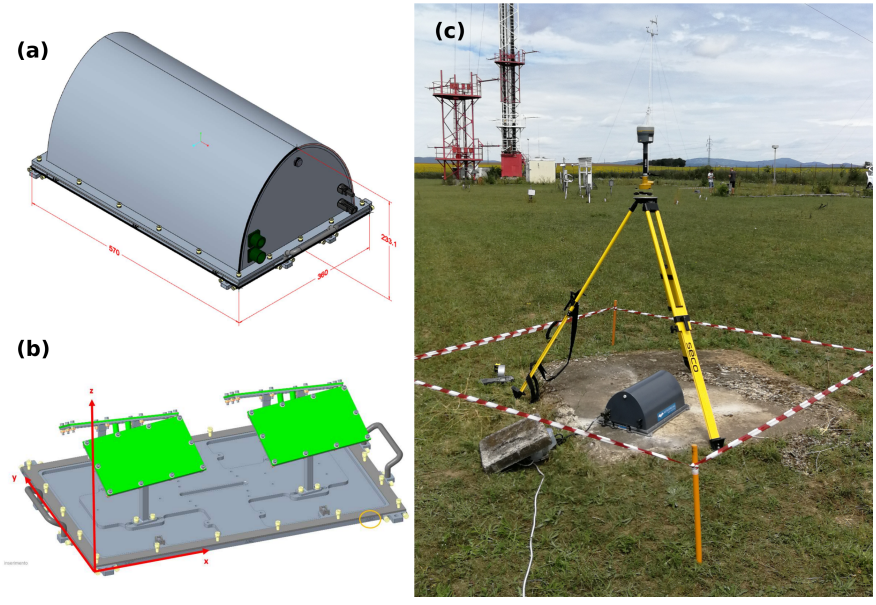

Fig. 1. (a) ECR-C model, (b) antennas under radome [5], (c) ECR141 during static GNSS positioning.

The theoretical RCS of the transponder can be determined from the gains of its components [6], [7]:

$$
\mathrm{RCS}=G_{\mathrm{RF}} \frac{G_{\mathrm{tx}} G_{\mathrm{rx}}}{4 \pi} \lambda^{2},
$$

where $G_{\mathrm{RF}}$ is the gain of the RF amplifying section, $G_{\mathrm{tx}}, G_{\mathrm{rx}}$ are the gains of the transmit and receive antennas, respectively, and $\lambda$ is the received signal's wavelength. For our devices, the same patch antenna types are used for receive/transmit, as well as for ascending/descending orientation, with a gain of $15 \mathrm{~dB}$. The RF chain consists of three amplifiers and a pair of bandpass filters $(4.9-6.2 \mathrm{GHz})$ before and after each amplifier to avoid interference from other devices, such as WiFi networks. With an expected overall RF gain of $50 \mathrm{~dB}$, the expected RCS of the transponders is $44 \mathrm{dBm}^{2}$. The characteristics of the used transponders are summarized in Table I.

TABLE I

TRANSPONDER CHARACTERISTICS AS SPECIFIED BY [5].

\begin{tabular}{ll}
\hline Size & $360 \times 570 \times 233 \mathrm{~mm}$ \\
Bandwidth & $5405 \pm 100 \mathrm{MHz}$ \\
Antennas & $2 \times(\mathrm{Rx}+\mathrm{Tx})$ ascending/descending \\
Antenna gain & $15 \mathrm{dBi}$ \\
Antenna beamwidth & $40^{\circ}$ (elevation), 20 (azimuth) \\
Antenna orientation & $32^{\circ}$ (elevation tilt), $12^{\circ}$ (azimuth squint) \\
RF gain & $50 \mathrm{~dB}$ \\
Expected RCS & $44.0 \mathrm{dBm}$ \\
Expected electrical delay & $10 \mathrm{~ns}(1.5 \mathrm{~m})$ \\
\hline
\end{tabular}

\section{EXPERIMENT SETUP}

Four transponders, located at test site JABO in Slovakia and WASS in the Netherlands, are evaluated in experiments covering nearly 1000 SAR acquisitions of the Sentinel-1 satellites. Here we discuss the two test sites and the characteristics of the time series.

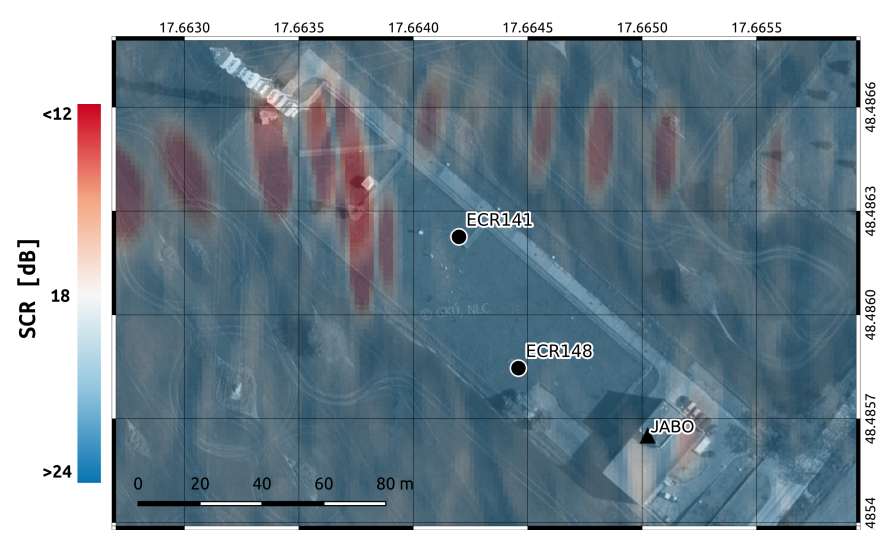

Fig. 2. Experiment setup with transponders 141 and 148 at the JABO meteorological station, Slovakia. The base-layer contains the simulated SCR superimposed on a grayscale orthomosaic [9]

\section{A. Test site JABO, Slovakia}

Transponder units 141 and 148 were installed at 9 July 2020 at a meteorological station near the permanent GNSS station JABO of the SKPOS network in Slovakia, see Fig. 2. The distance between the two units is $46.5 \mathrm{~m}$, which is ideal for the double-difference InSAR phase observations. The transponders are fastened on horizontal (leveled) concrete slabs. Assuming ascending and descending antenna symmetry, both units were precisely oriented w.r.t. the north of the Conventional Terrestrial Reference Frame (CTRF) [8], with the help of two points staked-out using RTK GNSS receivers connected to SKPOS service. The position of the transponders is selected such that it guarantees a high SCR. This is attained by estimating the site's clutter power from one year of Sentinel-1 time series prior to deployment, and conservatively assuming a transponder RCS of $30 \mathrm{dBm}^{2}$, equivalent to a $1 \mathrm{~m}$ leg-length triangular trihedral corner reflector. The resultant simulated SCR is superimposed on the orthomosaic in Fig. 2. To avoid interference of impulse response of the two transponders, they are separated from nearby point scatterers by at least two resolution cells in range $(\sim 6 \mathrm{~m})$ and azimuth direction $(\sim 42 \mathrm{~m})$ for both ascending and descending Sentinel1 tracks.

Both transponders are programmed to receive and transmit in VV polarisation for all regular Sentinel-1 acquisitions over the JABO station, see Table II. They are activated 4 minutes prior to the satellite overpass to warm up the RF chain and to stabilize the phase response, and deactivated 2 minutes afterwards. GNSS time synchronisation is scheduled each day at 12 a.m., such that it does not interfere with the planned activations.

\section{B. Test site WASS, the Netherlands}

The second experiment is performed at the TU Delft geodetic test site, WASS, located in Wassenaar, the Netherlands, see Fig. 3. We test the performance of transponder 100, an initial series unit covering a 21 months time series, and transponder 128 , which was manufactured in the same series as units 141 and 148 used in Slovakia. Apart from the transponders, the WASS test site includes six passive corner reflectors on a stable 
TABLE II

SENTINEL-1 ACQUISITION TIMES SCHEDULED FOR TRANSPONDERS 141 AND 148 AT THE JABO TEST SITE. THE SUFFIX BEHIND THE TRACK NUMBER INDICATES THE ASCENDING AND DESCENDING ORBIT DIRECTION.

\begin{tabular}{llll}
\hline Track & UTC & $\begin{array}{l}\text { incidence } \\
\text { angle }\end{array}$ & $\begin{array}{l}\text { zero-Doppler } \\
\text { direction }\end{array}$ \\
\hline $124 \mathrm{~d}$ & $05: 02$ & $37.14^{\circ}$ & $100.32^{\circ}$ \\
$051 \mathrm{~d}$ & $04: 54$ & $45.60^{\circ}$ & $98.79^{\circ}$ \\
$073 \mathrm{a}$ & $16: 43$ & $41.78^{\circ}$ & $260.48^{\circ}$ \\
$175 \mathrm{a}$ & $16: 35$ & $32.48^{\circ}$ & $258.93^{\circ}$ \\
\hline
\end{tabular}

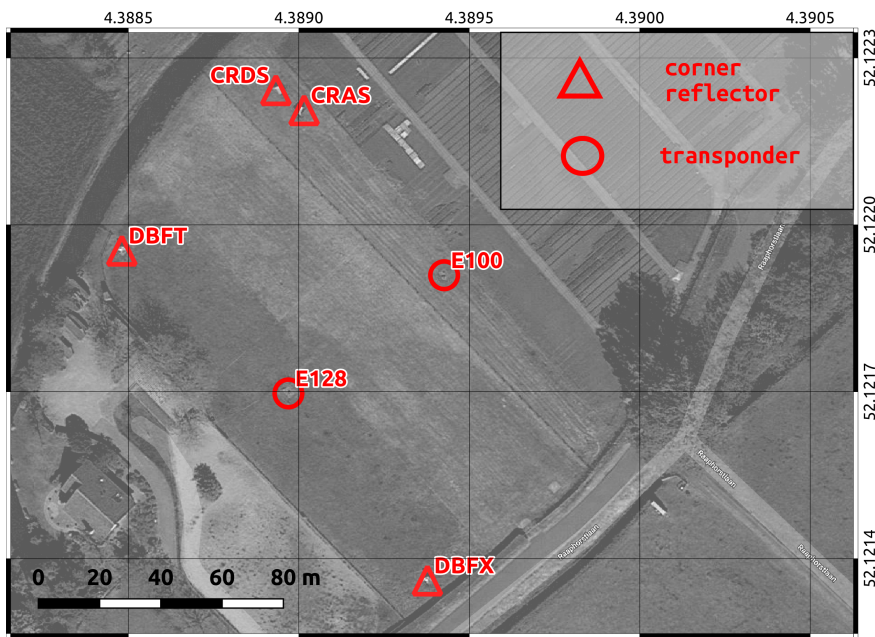

Fig. 3. Wassenaar test site, The Netherlands: experiment setup with transponders 100 and 128 and reference corner reflectors CRAS, CRDS, DBFT, and DBFX.

foundation. Two large square-based trihedral reflectors with an inner edge length of $1.425 \mathrm{~m}$ and a corresponding peak-RCS of $40.7 \mathrm{dBm}^{2}$ (C-band) are referred to as CRAS and CRDS for the ascending and descending orbit orientations, respectively. Two Integrated Geodetic Reference Stations (IGRS) [10] both contain double (ascending and descending) back-flipped triangular trihedral reflectors. The first, referred to as DBFT has an inner edge length of $0.9 \mathrm{~m}$ and a corresponding peakRCS of $29.5 \mathrm{dBm}^{2}$ (C-band), while the second, DBFX, has an effective edge length of $1.36 \mathrm{~m}$ and a corresponding peakRCS of $36.7 \mathrm{dBm}^{2}$ (C-band). All these reference reflectors are deployed since 2017 and their RCS and phase stability are well known. Transponders 100 and 128 form very short baselines w.r.t. these reference reflectors, and are scheduled for all regular Sentinel-1 acquisition times, see Tab. III. The long-term stability of the concrete slabs carrying the transponders has been verified by repeated levelling measurements, surveyed since 2013. We use meteorological data from KNMI station Voorschoten, at a distance of $4 \mathrm{~km}$ from the test site WASS.

\section{Sentinel-1 time series analysis}

The radiometric, interferometric, and positioning performance of the four transponders is analyzed using Sentinel-1 SLC time series acquired from two overlapping ascending and two overlapping descending tracks. Table IV summarizes the
TABLE III

SENTINEL-1 ACQUISITION TIMES SCHEDULED FOR TRANSPONDERS 100 AND 128 AT THE WASS TEST SITE. THE SUFFIX BEHIND THE TRACK NUMBER INDICATES THE ASCENDING AND DESCENDING ORBIT DIRECTION.

\begin{tabular}{llll}
\hline Track & UTC & $\begin{array}{l}\text { incidence } \\
\text { angle }\end{array}$ & $\begin{array}{l}\text { zero-Doppler } \\
\text { direction }\end{array}$ \\
\hline $110 \mathrm{~d}$ & $05: 58$ & $36.69^{\circ}$ & $100.54^{\circ}$ \\
037d & $05: 50$ & $44.65^{\circ}$ & $98.92^{\circ}$ \\
$161 \mathrm{a}$ & $17: 33$ & $41.76^{\circ}$ & $260.46^{\circ}$ \\
$088 \mathrm{a}$ & $17: 25$ & $33.24^{\circ}$ & $258.83^{\circ}$ \\
\hline
\end{tabular}

number of Sentinel-1 data used for the operational period of the tested transponders. The effective acquisition interval for the two Sentinel-1 satellites is 6-days. Due to the chosen settings of the transponders only data in VV polarisation is used for the analysis.

SAR time series analysis of the transponders is performed using the open-source toolbox GECORIS [11]. For the position of each transponder in each of the SLCs, an image patch of $10 \times 10$ resolution cells is selected and oversampled by a factor 32 in the frequency domain by zero-padding. Then, we estimate the precise peak position and amplitude by fitting a 2D elliptic paraboloid over a small image subpatch, centered at the oversampled amplitude maximum of the initial patch. This procedure guarantees a peak detection precision of better than $1 / 100$ pixel [12]-[14], which is equivalent to an uncertainty of $<2 \mathrm{~cm}$ and $<13 \mathrm{~cm}$ in the range and azimuth direction of the Sentinel-1 SLC products, respectively.

\section{RESUlTS}

In the following, we discuss the results of our experiments considering the amplitude behaviour, InSAR phase stability, and absolute positioning in sections IV-A-IV-C, respectively.

\section{A. Radiometry}

A transponder approximates an ideal radar point scatterer with a 2D sinc-like impulse response function (IRF). The instantaneous RCS of a transponder, per acquisition, is estimated using the peak method [15], [16]

$$
\mathrm{RCS}=\bar{\beta}_{0} \cdot \Delta_{\mathrm{az}} \cdot \Delta_{\mathrm{r}}\left[\mathrm{m}^{2}\right] \text {, }
$$

where $\bar{\beta}_{0}$ is the peak radar brightness obtained from the precisely estimated peak amplitude via the pixel scaling factor [17], and $\Delta_{\mathrm{az} / \mathrm{r}}$ are the azimuth and range resolution, respectively. The peak radar brightness, $\bar{\beta}_{0}$, is corrected for the noise-equivalent-sigma-zero (NESZ) [18] and for the clutter power. For our test sites, we estimate the clutter power from the Sentinel-1 SAR time series prior to the installation of the transponders, which is demonstrated to be $-9 \mathrm{~dB}$ on average and temporally stationary by [19].

Fig. 4 shows an example of the radar brightness for the two transponders at the JABO test site. The RCS time series of these two transponders, including the three months of clutter observed before their deployment, are shown in Fig. 5. The outliers for unit 148 in July 2020 are the consequence 
TABLE IV

SUMMARY OF THE FOUR TESTED TRANSPONDERS AND SENTINEL-1 DATA USED UNTIL 28 MARCH 2021

\begin{tabular}{ccllc}
\hline \multirow{2}{*}{ Transponder } & \multirow{2}{*}{ Location } & \multirow{2}{*}{$\begin{array}{l}\text { Operational } \\
\text { since }\end{array}$} & \multicolumn{2}{c}{ No. Sentinel-1A+B acquisitions } \\
\cline { 3 - 5 } & & $2019-06-19$ & $104+105$ & ascending \\
100 & WASS, Wassenaar, Netherlands & $56+58$ & $58+58$ \\
128 & WASS, Wassenaar, Netherlands & $2020-04-04$ & $41+42$ & $41+40$ \\
141 & JABO, Jaslovske Bohunice, Slovakia & $2020-07-09$ & $41+42$ & $41+40$ \\
\hline
\end{tabular}
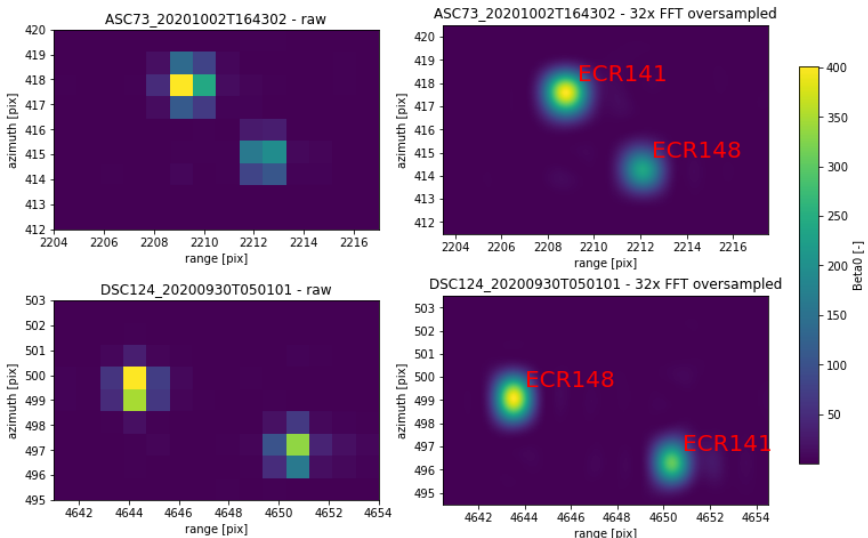

Fig. 4. The radar brightness $\beta_{0}$ image patch showing two transponders (units 141 and 148) at the JABO test site, from ascending track 73 (top row) and descending track 124 (bottom row) for a single acquisition. Left: Raw data, and right: oversampled data, factor 32 .

of a firmware problem, causing the unit not to switch on during these satellite overpasses. These outliers were removed from the time series analysis using the three median absolute deviations (MAD) criterion [20].

Fig. 6 shows an example of the oversampled radar brightness for all reflectors at the WASS test site.

The RCS time series statistics for all four transponders are summarized in Table V. The temporal average RCS of the units 128,141 , and 148 ranges from $42 \mathrm{dBm}^{2}$ to $45 \mathrm{dBm}^{2}$ across Sentinel-1 tracks, while the temporal average RCS of unit 100 , which is an older prototype, is approximately $4 \mathrm{~dB}$ lower. Note that $45 \mathrm{dBm}^{2}$ is equivalent to a triangular trihedral corner reflector with a leg-length longer than $2.0 \mathrm{~m}$. These values are in agreement with the theoretical value computed using (1).

a) Alignment sensitivity: Table $\mathrm{V}$ shows that the RCS averages differ between tracks, depending on incidence angle and zero-Doppler direction, see Tab. II and III, resulting in antenna misalignment and subsequently RCS attenuation. The misalignment in the elevation $(\Delta \theta)$ is computed as the acquisition's incidence angle minus the antenna's elevation tilt $\left(32^{\circ}\right)$ and the misalignment in the azimuth $(\Delta \alpha)$ is computed as the acquisition's zero-Doppler angle minus $90^{\circ}$ minus the antenna's azimuth squint $\left(12^{\circ}\right)$. Fig. 7 shows this average RCS plotted against a misalignment in elevation and azimuth angles. We observe maximally $3 \mathrm{~dB}$ RCS loss for $13^{\circ}$ and $-3^{\circ}$ misalignment in elevation and azimuth angles, respectively. Compared to a triangular trihedral corner reflector,
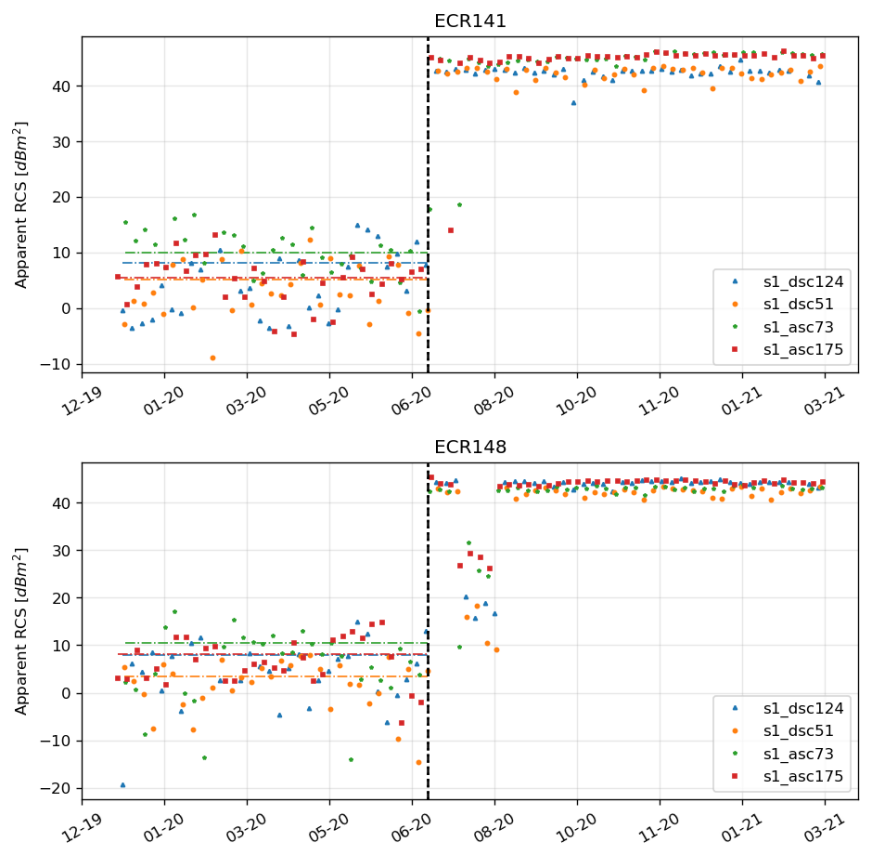

Fig. 5. RCS time series of transponders 141 and 148 at the JABO test site, for the four Sentinel-1 tracks. The dashed vertical line represents the installation time.

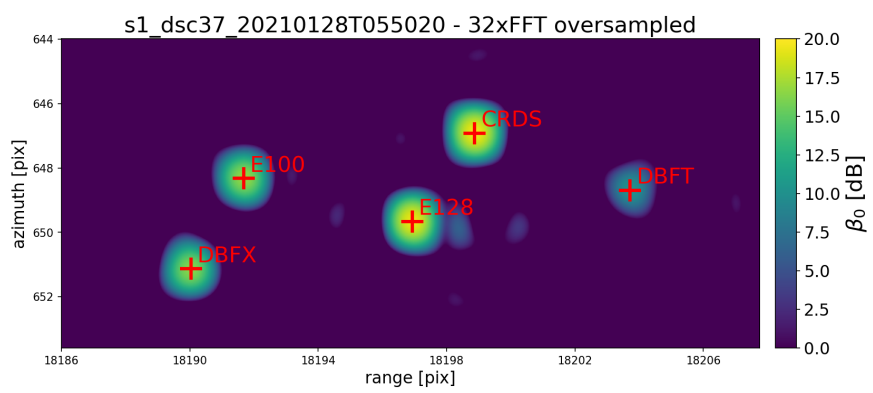

Fig. 6. The radar brightness $\beta_{0}$ image patch showing all reflectors at the WASS test site.

an equivalent misalignment would yield an attenuation of $\sim 1.5 \mathrm{~dB}$. Considering a SCR of $20 \mathrm{~dB}$, a $3 \mathrm{~dB}$ loss increases the phase error by $\sim 0.1 \mathrm{~mm}$ [19], [21]. We approximate the observed attenuation by a quadratic polynomial via a weighted-least-squares (WLS) fit (excluding the data from prototype transponder 100 due to its constant offset). The only large residual appears for unit 128 , track 37 , which may be due to a slightly erroneous antenna orientation within the sealed 
TABLE V

RADIOMETRIC STATISTICS OF THE FOUR TRANSPONDERS ON FOUR INDEPENDENT SENTINEL-1 TIME SERIES,

\begin{tabular}{|c|c|c|c|c|c|c|c|}
\hline \multirow[t]{2}{*}{ Transponder } & \multirow{2}{*}{$\begin{array}{c}\text { No. } \\
\text { acquisitions }\end{array}$} & \multirow[t]{2}{*}{ Track } & \multicolumn{2}{|c|}{ Misalignment [deg] } & \multicolumn{2}{|c|}{$\mathrm{RCS}\left[\mathrm{dBm}^{2}\right]$} & \multirow{2}{*}{$\begin{array}{c}\text { Avg. SCR } \\
{[\mathrm{dB}]}\end{array}$} \\
\hline & & & $\Delta$ elevation & $\Delta$ azimuth & mean & std & \\
\hline \multirow[t]{4}{*}{100} & 107 & $37 d$ & 4.7 & -1.5 & 37.25 & .58 & 28.65 \\
\hline & 106 & $110 \mathrm{~d}$ & 12.7 & -3.1 & 38.41 & .68 & 29.41 \\
\hline & 104 & $161 \mathrm{a}$ & 9.8 & 2.5 & 37.74 & .46 & 29.24 \\
\hline & 105 & $88 \mathrm{a}$ & .2 & .8 & 40.30 & .46 & 33.40 \\
\hline \multirow[t]{4}{*}{128} & 58 & $37 d$ & 4.7 & -1.5 & 40.26 & .69 & 31.66 \\
\hline & 58 & $110 \mathrm{~d}$ & 12.7 & -3.1 & 41.59 & .68 & 32.59 \\
\hline & 56 & $161 d$ & 9.8 & 2.5 & 42.69 & .51 & 34.19 \\
\hline & 58 & $88 \mathrm{a}$ & .2 & .8 & 44.90 & .30 & 38.00 \\
\hline \multirow[t]{4}{*}{141} & 41 & $124 d$ & 5.1 & -1.7 & 42.71 & .42 & 34.55 \\
\hline & 40 & $51 \mathrm{~d}$ & 13.6 & -3.2 & 42.45 & .63 & 37.38 \\
\hline & 41 & $73 a$ & 9.8 & 2.5 & 45.19 & .58 & 35.20 \\
\hline & 42 & $175 \mathrm{a}$ & .5 & .9 & 45.18 & .40 & 39.75 \\
\hline \multirow[t]{4}{*}{148} & 37 & $124 d$ & 5.1 & -1.7 & 42.71 & .42 & 34.55 \\
\hline & 36 & $51 \mathrm{~d}$ & 13.6 & -3.2 & 42.26 & .62 & 36.85 \\
\hline & 37 & $73 a$ & 9.8 & 2.5 & 42.90 & .35 & 32.46 \\
\hline & 38 & $175 \mathrm{a}$ & .5 & .9 & 44.22 & .36 & 36.09 \\
\hline
\end{tabular}

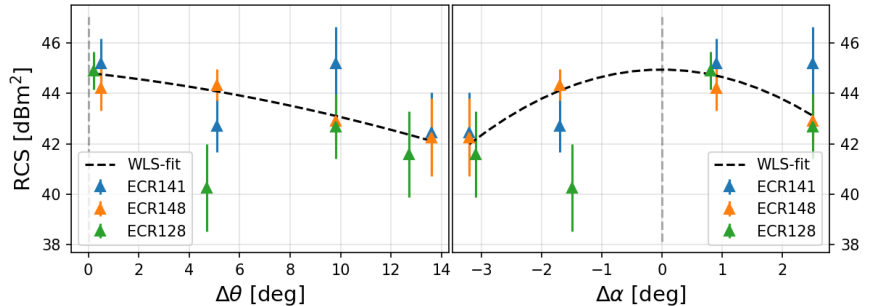

Fig. 7. RCS versus antenna misalignment in elevation $(\Delta \theta)$ and azimuth $(\Delta \alpha)$ angles. A weighted-least-squares fit approximates the attenuation by a quadratic polynomial. Error-bars are 2.5 sigma.

casing of the transponder.

b) Temporal stability: Comparing the temporal RCS stability of the transponders with conventional corner reflectors, see Table VI, we find that despite the higher average RCS of the transponders, their RCS standard deviations, $\sigma_{\mathrm{RCS}}$, are significantly higher. For the WASS test site, both the reflectors and the transponders experience identical clutter conditions, which implies that the observed $\sigma_{\mathrm{RCS}}$ is not influenced by the clutter. In fact, the temporal RCS stability of the transponders is comparable to the DBFT reflector, which has a more than $10 \mathrm{~dB}$ lower RCS. In section IV-B we show the implications of the RCS stability on the temporal phase stability.

c) Susceptibility to systematic temporal variations: For a correct interpretation of transponder time series, it is important to understand whether the RCS is susceptible to systematic temporal variations. The scatter plots in Fig. 8 show RCS time series of the transponders plotted againts the hourly surface temperatures. The ascending tracks, i.e., the yellow triangles in Fig. 8, acquired in the afternoon, typically experience a higher temperature range over the seasons than the descending tracks.

The RCS variability of the units in the WASS test site does not show a significant correlation with temperature, and
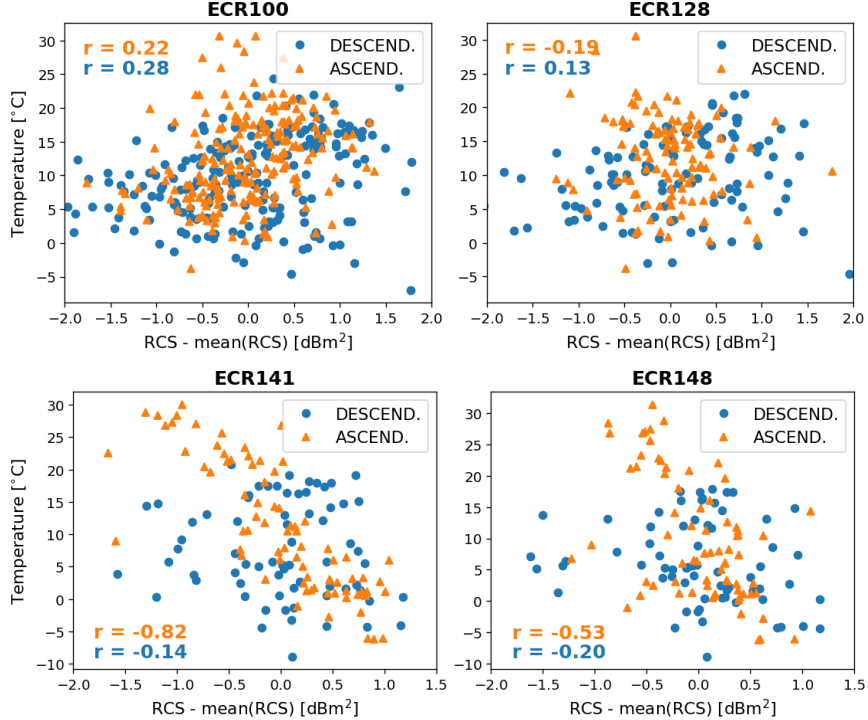

Fig. 8. RCS variability versus surface temperature for the four transponders, including Pearson's sample correlation coefficient $r$.

neither do the descending data of the JABO test site. However, there is a significant correlation of -0.82 and -0.53 for the ascending data of the JABO test site, for units 141 and 148 , respectively. This temperature dependency is observed (i) in only one of the two test sites (JABO), (ii) in only one of the two viewing geometries (ascending), (iii) for environmental temperatures higher than $20^{\circ} \mathrm{C}$, which only occur in the ascending (afternoon) orbits, and (iv) in two independent units (141 and 148). This suggests that temperature variations do not necessarily affect the RCS, but if they do, it occurs mainly for temperatures higher than $20^{\circ} \mathrm{C}$. In those cases, an increase in temperature results in a (slight) decrease of RCS for these acquisitions. Note that this would lead to a $1 \mathrm{dBm}^{2}$ reduction 
TABLE VI

RCS STANDARD DEVIATIONS FOR CORNER REFLECTORS AND TRANSPONDERS, IN [DBM ${ }^{2}$ ].

\begin{tabular}{lllcllll}
\hline \multirow{2}{*}{ Target } & \multirow{2}{*}{ Type } & \multirow{2}{*}{ Site } & \multirow{2}{*}{ average RCS } & \multicolumn{4}{c}{$\sigma_{\text {RCS }}$} \\
\cline { 5 - 8 } & & & & ASC88 & ASC161 & DSC37 & DSC110 \\
\hline CRAS / CRDS & reflector & WASS & 39.0 & .13 & .19 & .14 & .19 \\
DBFX & reflector & WASS & 35.4 & .24 & .21 & .16 & .22 \\
DBFT & reflector & WASS & 28.6 & .44 & .42 & .47 & .44 \\
100 & transponder & WASS & 38.4 & .58 & .68 & .46 & .46 \\
128 & transponder & WASS & 42.4 & .69 & .68 & .51 & .30 \\
141 & transponder & JABO & 43.9 & .42 & .63 & .58 & .40 \\
148 & transponder & JABO & 43.4 & .25 & .62 & .35 & .36 \\
\hline
\end{tabular}

in RCS, hence, a $1 \mathrm{~dB}$ reduction in SCR, which is equivalent to less than $0.2^{\circ}$ phase error for an $\mathrm{SCR}>30$.

\section{B. InSAR phase stability}

Deploying compact transponders is arguably most interesting for applications that use the phase information, i.e., SAR interferometry. This requires an assessment of the reliability and stability of the transponder phase. At the WASS test site we evaluate this using a configuration that combines transponders and corner reflectors at distances of less than $70 \mathrm{~m}$, which results in an atmospheric differential signal that is maximally $0.1 \mathrm{~mm}$ in the most extreme situations, but on average $0.03 \mathrm{~mm}$ [22], corresponding to $1.3^{\circ}$ and $0.4^{\circ}$ for $\mathrm{C}$-band, respectively. This allows us to evaluate the temporal coherence, i.e. the phase stability, of the transponders, as the phase variance should be dominated by the clutter, described by the SCR of the transponders, and the sensor's thermal noise.

Flattened and topography-corrected interferograms were computed for all Sentinel-1 stacks, and subsequently interferometric phase time series, evaluated at the IRF peaks, were used to compute double-difference phase time series between transponders and reflectors. Fig. 9 shows the double-difference (DD) phase time series between a transponder and a reference reflector, both for the ascending and the descending oriented antennas, for all Sentinel-1 tracks. As the seasonal signal is apparent in the time series, we also plot the surface temperature readings of the nearest meteo-station (Voorschoten) obtained at the whole hour closest to the Sentinel-1 acquisition.

To verify that this signal is not coming from the reference reflectors, we also compute DD time series between the independent reference reflectors, see Fig. 10. Since the seasonal signal is not visible for this baseline, we can attribute the temporal variability in Fig. 9 uniquely to the transponders. Likewise, scatter plots of the LOS displacement against the temperature, see Fig.11, from the ascending tracks, show a significant correlation for the transponders, while practically no correlation for CRs. The results from repeated levelling measurements between the concrete slabs carrying the reflectors exclude an actual displacement as a potential cause of the seasonal signal. Therefore, the phase measurements of the transponders are indeed sensitive to the temperature variations, with a typical dependency of $0.07-0.15 \mathrm{~mm} /{ }^{\circ} \mathrm{C}$. This phase sensitivity to temperature was also observed for other compact transponder prototypes by [23], with a correlation coefficient of 0.8 .

For the transponders at test site JABO, we cannot compute independent phase DD's as there is no nearby reference corner reflector. Therefore, Fig. 12 only shows phase DD's, converted to LOS displacements, over the very short baseline between units 141 and 148. Assuming the same temperature dependency for both the units, it should cancel out over this baseline. However, a residual correlation of the InSAR phases with the surface temperature is apparent. Unfortunately, in this case we cannot rule out actual subsidence or uplift of one of the concrete blocks carrying the transponders.

In Fig. 12 we also compare the LOS displacement time series with the precipitation and snow cover data of test site JABO. The highest displacement gradient aligns with the time of the highest cumulative precipitation, in September 2020. The sudden $2 \mathrm{~mm}$ phase jumps in January and February of 2021 are clearly a consequence of the snow and ice cover on the transponder's radomes, as shown by the snow cover time series in Fig. 12.

To compensate for the influence of temperature on phase, the transponders would need to have an active temperature control system, such as used by calibration transponders [24]. This would, however, increase the complexity, energy consumption, and consequently the cost of the transponders.

Instead, we find that secular and seasonal effects in the time series can be effectively modelled in the post-processing, as long as they remain trend-stationary. Our results show that rather than using a universal correction, each individual transponder requires unique modelling. For each track, we estimate and remove the (seasonal) temperature-dependent signal from the InSAR DD time series $\Delta \phi_{t}$ for epochs $t \in\left(t_{1} ; t_{N}\right)$, assuming the functional model

$$
\mathbb{E}\left\{\left[\begin{array}{c}
\Delta \phi_{t_{1}} \\
\Delta \phi_{t_{2}} \\
\vdots \\
\Delta \phi_{t_{N}}
\end{array}\right]\right\}=-\frac{4 \pi}{\lambda}\left[\begin{array}{cc}
1 & T_{t_{1}} \\
1 & T_{t_{2}} \\
\vdots & \vdots \\
1 & T_{t_{N}}
\end{array}\right]\left[\begin{array}{c}
C \\
K_{T}
\end{array}\right],
$$

where $C$ is the constant offset, $T$ the measured temperatures, and $K_{T}$ is the temperature-dependent scaling factor. The timedependent trend (drift) was not parameterized in the (3), as 

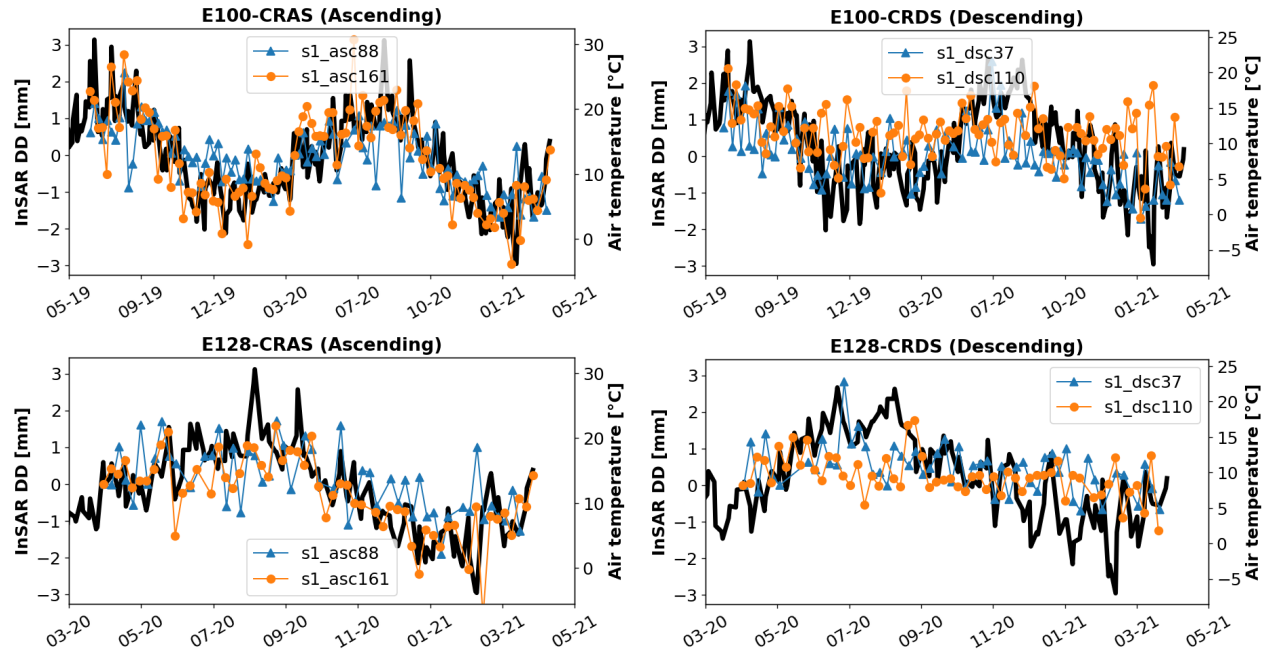

Fig. 9. InSAR phase double-difference (DD) for units 100 and 128, relative to a reference corner reflector, plotted against temperature for test site WASS.
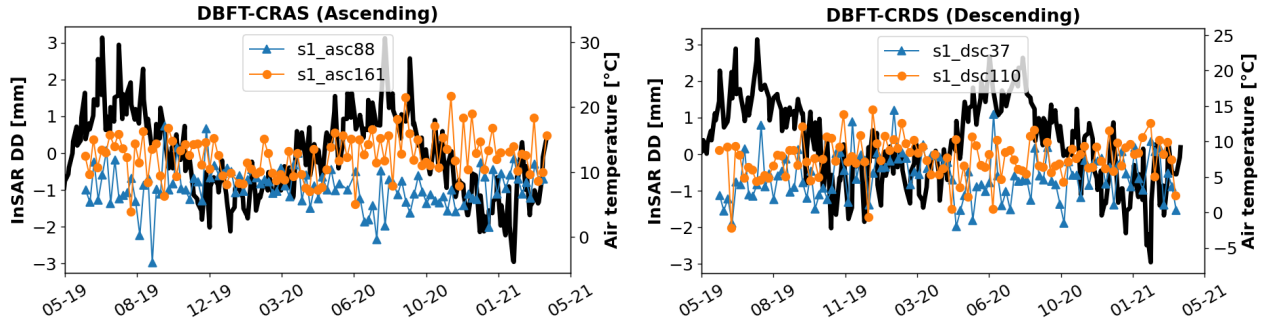

Fig. 10. InSAR phase double-differences (DD) for two reference corner reflectors, plotted against air temperature for test site WASS.
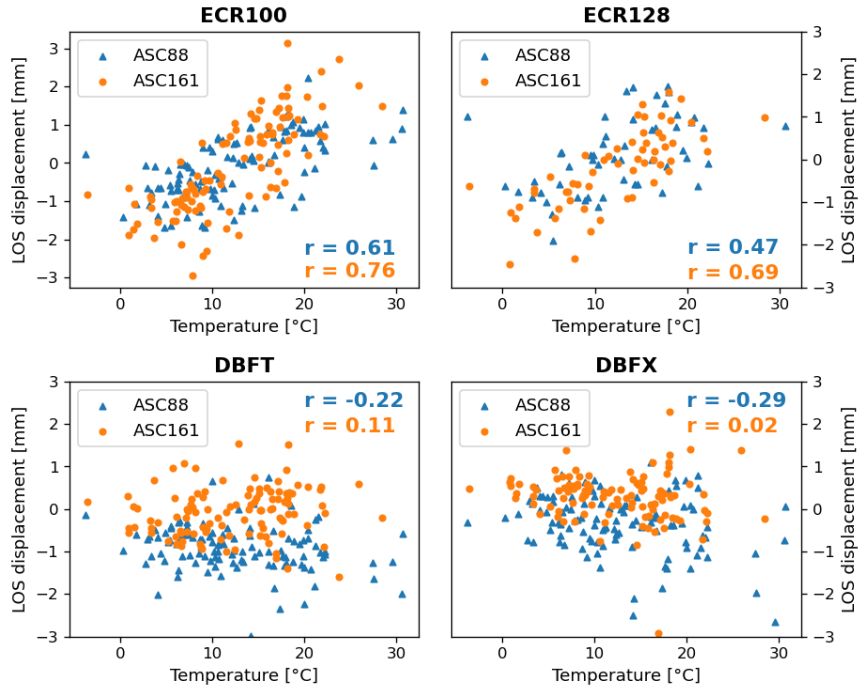

Fig. 11. InSAR LOS displacement of transponders (units 100 and 128) and reflectors (DBFT and DBFX) plotted against temperature, for test site WASS.

no displacement trend is observed from the levelling measurements. However, we estimate the drift from the residuals and test its significance using the parameter significance test [25]. The estimated drift values are reported in Table VII. For unit 100 , in track $88 \mathrm{a}$ and $37 \mathrm{~d}$, the estimated drifts are significant (level of significance $\alpha=0.01$ ), while neither of
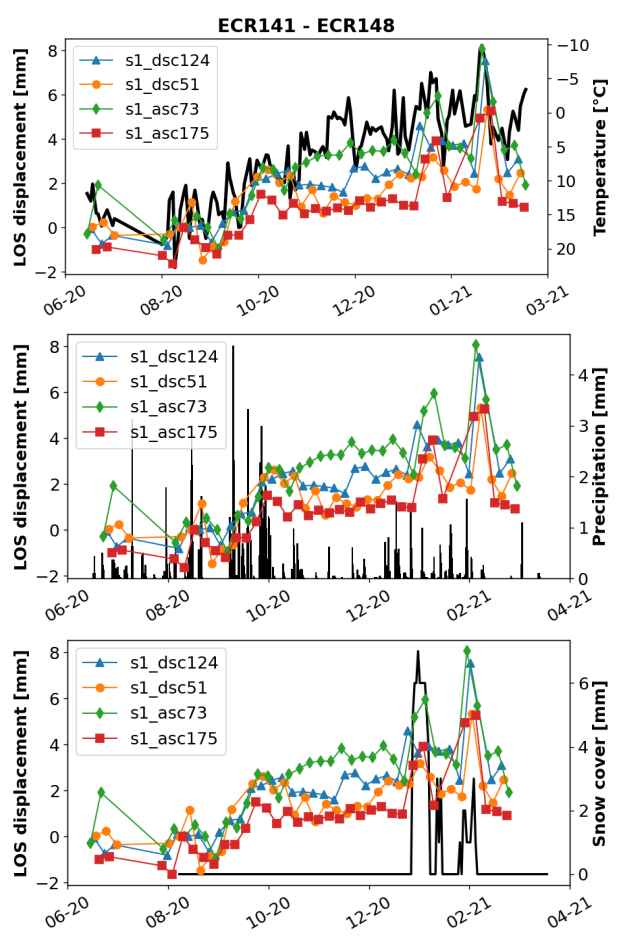

Fig. 12. Time series of InSAR phase double-differences (LOS displacement) between units 141 and 148, and surface temperature, precipitation, and snow cover for test site JABO. 
TABLE VII

INSAR DOUBLE-DIFFERENCE (DD) PHASE STANDARD DEVIATION (STD) AND DRIFT, FOR TRANSPONDERS 100, 128, 141, AND 148, AND FOR REFLECTORS CRAS, CRDS, DBFT, AND DBFX. ABBREVIATION DETR. STANDS FOR DETRENDED.

\begin{tabular}{|c|c|c|c|c|c|c|}
\hline \multirow[t]{2}{*}{ Baseline } & \multirow[t]{2}{*}{ Track } & \multicolumn{4}{|c|}{$\begin{array}{cc}\text { InSAR DD phase STD }[\mathrm{mm}] \\
\text { predicted } & \text { observed }\end{array}$} & \multirow{2}{*}{$\begin{array}{c}\text { Residual drift } \\
\text { [mm/yr] } \\
\pm 1 \sigma\end{array}$} \\
\hline & & SCR & NAD & raw & detr. & \\
\hline \multirow[t]{2}{*}{ 100-CRAS } & $88 \mathrm{a}$ & .2 & .5 & .8 & .5 & $-0.5 \pm 0.1$ \\
\hline & $161 \mathrm{a}$ & .2 & .4 & 1.2 & .6 & $-0.3 \pm 0.2$ \\
\hline \multirow[t]{2}{*}{-CRDS } & $37 \mathrm{~d}$ & .2 & .6 & .8 & .6 & $-0.4 \pm 0.1$ \\
\hline & $110 \mathrm{~d}$ & .2 & .6 & .7 & .6 & $-0.3 \pm 0.1$ \\
\hline \multirow[t]{2}{*}{ 128-CRAS } & $88 \mathrm{a}$ & .2 & .3 & .9 & .7 & $-0.7 \pm 0.4$ \\
\hline & $161 \mathrm{a}$ & .2 & .5 & 1.0 & .7 & $-0.6 \pm 0.3$ \\
\hline \multirow[t]{2}{*}{-CRDS } & $37 \mathrm{~d}$ & .2 & .6 & 6 & .6 & $-0.4 \pm 0.3$ \\
\hline & $110 \mathrm{~d}$ & .2 & .6 & .5 & .5 & $-0.6 \pm 0.3$ \\
\hline \multirow[t]{2}{*}{ DBFT-CRAS } & $88 \mathrm{a}$ & .4 & .4 & .5 & .5 & $-0.2 \pm 0.1$ \\
\hline & $161 \mathrm{a}$ & .4 & .4 & .6 & .6 & $+0.2 \pm 0.1$ \\
\hline \multirow[t]{2}{*}{-CRDS } & $37 \mathrm{~d}$ & .5 & .5 & .6 & .6 & $0.0 \pm 0.1$ \\
\hline & $110 \mathrm{~d}$ & .4 & .5 & .5 & .5 & $0.0 \pm 0.1$ \\
\hline \multirow[t]{2}{*}{ DBFX-CRAS } & $88 \mathrm{a}$ & .3 & .3 & .5 & .5 & $0.0 \pm 0.1$ \\
\hline & $161 \mathrm{a}$ & .3 & .3 & .6 & .6 & $0.0 \pm 0.1$ \\
\hline \multirow[t]{2}{*}{ - CRDS } & $37 \mathrm{~d}$ & .3 & .3 & .5 & .5 & $-0.3 \pm 0.1$ \\
\hline & $110 \mathrm{~d}$ & .3 & .3 & .5 & .5 & $-0.1 \pm 0.1$ \\
\hline \multirow[t]{4}{*}{$141-148$} & $73 a$ & .1 & .3 & 1.7 & .8 & $+0.9 \pm 0.8$ \\
\hline & $175 a$ & .1 & .3 & 1.3 & .9 & $+1.0 \pm 0.9$ \\
\hline & $51 \mathrm{~d}$ & .1 & .3 & 1.9 & 1.1 & $+0.9 \pm 1.1$ \\
\hline & $124 d$ & .1 & .3 & 1.6 & 1.0 & $+1.1 \pm 1.0$ \\
\hline
\end{tabular}

the estimated drifts of unit 128 could be proven significant. Since the estimated residual drifts over the baseline between the corner reflectors are not significant, see Fig. 10, we reject the hypothesis that reference reflectors have an influence on the observed drift of the transponders. Longer time series would be needed to obtain a more reliable estimate of the phase drift. Nonetheless, we can safely state that it is smaller than $1 \mathrm{~mm}$ per year.

After removing the estimated temperature-dependent signal and the residual drift, we assume that the phase residuals are representative of the phase noise and compute the standard deviation (STD) of the residuals. Table VII shows the estimated STDs for the transponder-reflector (T/R), reflectorreflector $(\mathrm{R} / \mathrm{R})$, and transponder-transponder $(\mathrm{T} / \mathrm{T})$ baselines before ('raw') and after the trend removal ('detrended'). We compare the estimated STD with the STD predicted using the normalized amplitude dispersion (NAD) [26] and the temporal average SCR [21]. For the reflectors CRAS and CRDS, we have a reliable estimate of their long-term phase STD. Their undifferenced single epoch phase STD is $\sigma_{\psi_{C R}}=0.11 \mathrm{~mm}$ [19]. Therefore, an estimate of the double-difference phase STD for a T/R baseline is obtained by error propagation (assuming uncorrelated measurements) as:

$$
\sigma_{\Delta \phi_{\mathrm{TR}}}=\left(2 \sigma_{\psi_{\mathrm{R}}}^{2}+2 \sigma_{\psi_{\mathrm{T}}}^{2}\right)^{1 / 2}
$$

where $\sigma_{\psi_{\mathrm{T}}}$ is computed either from NAD or SCR. Table VII shows that the SCR-based estimation of the phase STD gives overly optimistic values. As the clutter of the transponders

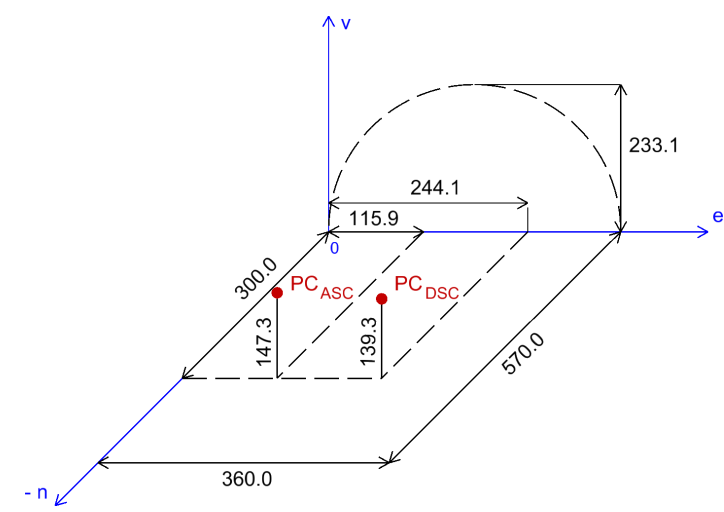

Fig. 13. Transponder dimensions and local topocentric offsets for ascending/descending antennas' phase centers (PC), in millimetres.

has not changed over the monitored period, the assumption of temporal ergodicity fails for the time series of the transponders' peak responses. In other words, the RCS variations are fully displayed in the phase instability. Therefore, the NAD provides a better STD proxy for the transponders.

Removing the trend and seasonal components lowers the STDs, cf. Table VII, where the most notable improvement is observed for the ascending tracks, which are more affected by temperature variations. For T/R baselines with units 100 and 128, we observe an average STD of $0.6 \mathrm{~mm}$ across all Sentinel-1 tracks. For T/T baseline 141-148, at test site $\mathrm{JABO}$, the phase shifts caused by the temporary snow/ice cover increase the estimated phase STD up to $1.1 \mathrm{~mm}$. The standard deviations of the undifferenced single epoch phase measurements of the transponders $\left(\sigma_{\psi_{T}}\right.$ in (4)) vary between 0.3 and $0.8 \mathrm{~mm}$.

\section{Absolute Positioning}

The positions of the transponder's antenna phase centres (both ascending and descending) in a Terrestrial Reference Frame (TRF) were determined applying a two-step procedure. First, we determined the coordinates of the transponder reference point, i.e., the northwestern corner of the base-plate, see Fig. 13, using GNSS. For the JABO test site, we used static GNSS observations for one hour (with a geodetic-grade receiver Trimble R10), connected to the ETRS89 coordinate reference system (ETRF2000 reference frame) via the nearby permanent reference station JABO (SKPOS network). For the WASS test site, we used four 90-seconds GNSS RTK observations (with a geodetic-grade receiver Trimble R8), connected to the ETRS89 coordinate reference system (ETRF2000 reference frame) using the NETPOS processing service of the Dutch Kadaster. Second, we computed the phase centre coordinates, for each of the antennas, from the reference point coordinates using local coordinate offsets supplied by the manufacturer, see Fig. 13.

The accuracy (repeatability) of the TRF coordinates is 1$2 \mathrm{~cm}$ in the horizontal and $3 \mathrm{~cm}$ in the vertical direction. Orbit state vectors of Sentinel-1 satellites are given in the ITRF2014 reference frame with a sampling rate of 10 seconds, determined by the on-board GNSS receiver. 
Absolute Positioning Errors (APE) are epoch-wise differences between the detected subpixel peak coordinates and the expected radar coordinates computed from the precise TRF positions via the inverse range-Doppler equations [27], correcting for all SAR timing biases. The APE in range $(\mathrm{rg})$ and azimuth (az) is computed as:

$$
\begin{aligned}
& \mathrm{APE}_{\mathrm{rg}}=\left(\tau_{\text {peak, IPF }}-\tau_{\text {predicted }}\right) \cdot c \\
& \mathrm{APE}_{\mathrm{az}}=\left(t_{\text {peak, IPF }}-t_{\text {predicted }}\right) \cdot v_{\text {zeroDoppler }},
\end{aligned}
$$

where $v_{\text {zeroDoppler }}$ is the satellite's ground-track zero-Doppler velocity. $\tau_{\text {peak, IPF }}$ and $t_{\text {peak, IPF }}$ are the azimuth and range time, respectively, of the sub-pixel peak positions in the SLC images as processed by the Sentinel-1's instrument processing facility (IPF). Predicted timings, $\tau_{\text {predicted }}$ and $t_{\text {predicted }}$, are composed of individual timing biases, i.e.,

$$
\begin{aligned}
& \tau_{\text {predicted }}=\tau_{\text {ITRF }}+\Delta \tau_{\mathrm{SET}}+\Delta \tau_{\text {tropo }}+\Delta \tau_{\text {iono }}+\Delta \tau_{\text {Doppler }}, \\
& t_{\text {predicted }}=t_{\text {ITRF }}+\Delta t_{\text {SET }}+\Delta t_{\text {bistatic }}+\Delta t_{\text {FM-rate }},
\end{aligned}
$$

where:

- ITRF represents positions directly obtained solving the range-Doppler equations from GNSS-determined coordinates in ITRS (ITRF2014 reference frame) at the particular acquisition epoch. The initial coordinates in ETRS89 (ETRF2000 reference frame) are first transformed to ITRS at the particular acquisition epoch, hence reflecting the plate motion.

- SET represents timing corrections computed from topocentric solid earth tides displacements, hence transforming from a 'tide free' position (ITRF) to the instantaneous position as seen by the satellite (adding a permanent "mean tide", as well as a periodic components of tidal displacement using IERS SET displacement models [8]).

- tropo is the range timing correction for the slant tropospheric signal delay (modelled using the ECMWF ERA5 model [28]).

- iono is the range timing correction for the slant ionospheric signal delay (modelled using the CODE IGS global ionospheric model [29]).

- bistatic is the residual bistatic correction of the Sentinel-1 IPF in the azimuth timing [14].

- Doppler are Doppler-centroid-induced range timing corrections [14], and

- FM represents the FM-rate mismatch of Sentinel-1 IPF in the azimuth timing [14].

Fig. 14 shows these corrections for transponder 141. Individual points in the figure represent epoch-wise SLC measurements. To verify the accuracy of the established APE computation framework, we compute APE time series for the four reference reflectors at test site WASS, see Fig. 15. The observed APE and its temporal variance are limited by the Cramer-Rao Lower Bound (CRB) of the peak variance, determined by the reflector's SCR and the azimuth/range SLC resolutions [30]. The accuracy of the GNSS-determined TRF coordinates is 1$2 \mathrm{~cm}$ in the horizontal and $3 \mathrm{~cm}$ in the vertical direction. The Sentinel-1 orbital state-vectors have a 3D RMS of $5 \mathrm{~cm}$

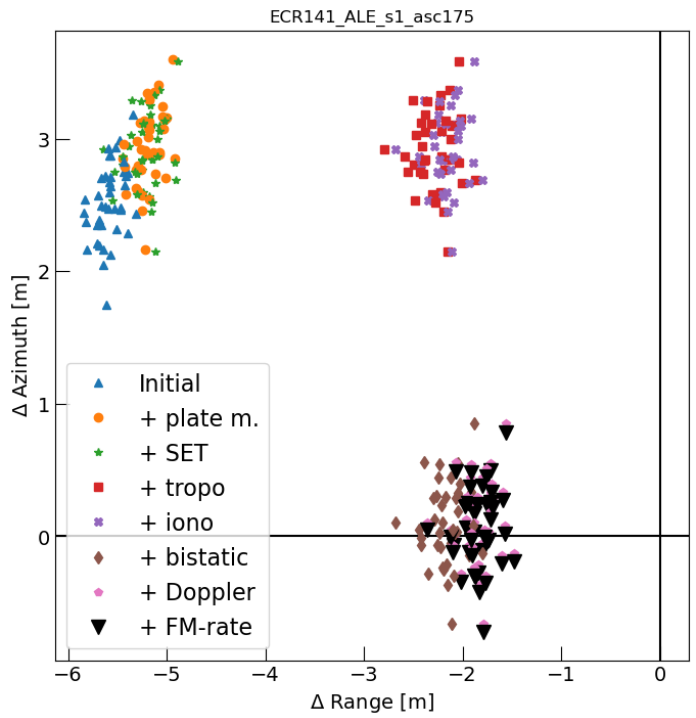

Fig. 14. Absolute Positioning Errors (APE) of transponder 141 from ascending track.

[31]. According to the cross-validation of the independently generated orbit solutions by [31], an orbit accuracy of $\sim 3 \mathrm{~cm}$ can be assumed. Considering the limited spatio-temporal resolution of the ERA5 model used for troposheric delay correction, and considering the RMS values of the TEC maps of CODE ionospheric models, both tropospheric and ionospheric delay corrections could be assumed to exhibit an accuracy of $\sim 10 \mathrm{~cm}[22]$.

Using simple error propagation, these effects contribute to an overall prediction uncertainty (repeatability) of $\sim 11 \mathrm{~cm}$ in range and $\sim 4 \mathrm{~cm}$ in azimuth. The average SCR of reflectors CRAS and CRDS, varies between 28-32 dB, yields a CRB of $28 \mathrm{~cm}$ and $4 \mathrm{~cm}$ in the azimuth and range directions, respectively. For these CRs, we achieve an average STD of $42 \mathrm{~cm}$ and $13 \mathrm{~cm}$ in the azimuth and range directions, respectively. For Sentinel-1 IW products, [14] reports an achievable STD limit of $49.2 \mathrm{~cm}$ and $8.3 \mathrm{~cm}$ for azimuth and range, respectively, given $1.5 \mathrm{~m}$ triangular trihedral reflectors. Therefore, we consider our APE computation framework sufficient for precise APE analysis of the transponders.

Here, the absolute SAR positioning accuracy of the transponders is evaluated. In Table VIII, average observed APE and its temporal standard deviation (STD) are reported.

Fig. 16 shows histograms of APE time series for the tested transponders. Observed systematic differences in the range coordinate are primarily caused by the internal electronic delay of the transponders. An approximate internal electronic delay of $\sim 1.5 \mathrm{~m}\left(10^{-9} \mathrm{~s}\right)$, including the antennas and protective radome, was estimated by [5]. However, the observed average range differences vary between $-1.24 \mathrm{~m}$ to $-2.10 \mathrm{~m}$. Moreover, different internal delays are observed across the individual transponders and between ascending and descending tracks, see Fig. 17. Fig. 18 shows average range delays plotted against the antenna misalignment in elevation and azimuth angles. We observe nonsystematic shifts between individual transponders. We also observe an apparent shift 

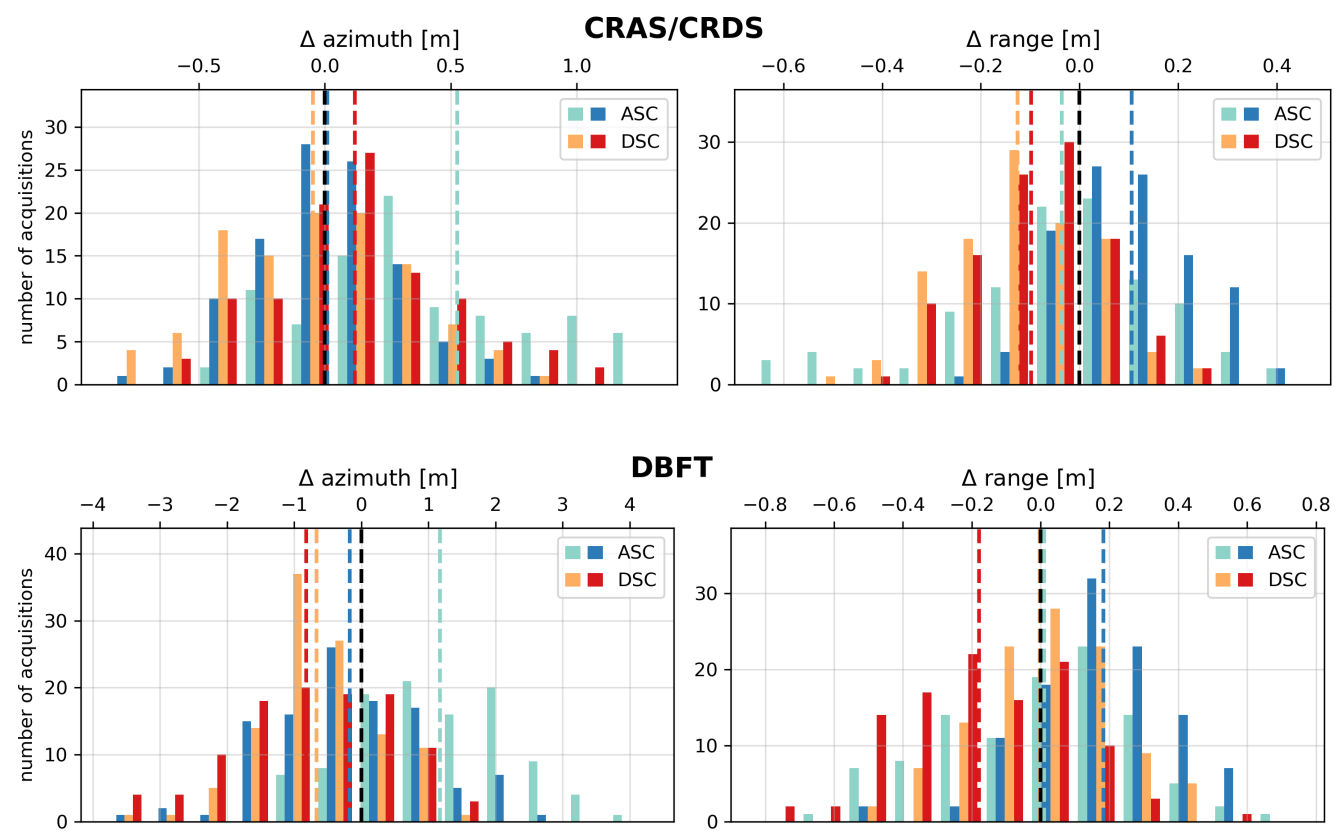

Fig. 15. Absolute Positioning Errors (APE) of the reference corner reflectors at test site WASS.

TABLE VIII

Absolute Positioning ERrors (APE) OF THE TESTED tranSPONDERS ON SENTINEL-1 TIME SERIES.

\begin{tabular}{|c|c|c|c|c|c|}
\hline \multirow[t]{2}{*}{ Transponder } & \multirow[t]{2}{*}{ Track } & \multicolumn{4}{|c|}{$\mathrm{APE} \pm 1 \sigma[\mathrm{cm}]$} \\
\hline & & \multicolumn{2}{|c|}{ azimuth } & \multicolumn{2}{|c|}{ range } \\
\hline \multirow[t]{4}{*}{100} & $88 \mathrm{a}$ & 14.0 & \pm 36.6 & -144.3 & \pm 13.5 \\
\hline & $161 \mathrm{a}$ & 24.2 & \pm 32.7 & -136.5 & \pm 14.1 \\
\hline & $37 \mathrm{~d}$ & -57.8 & \pm 39.7 & -133.3 & \pm 12.5 \\
\hline & $110 \mathrm{~d}$ & -2.0 & \pm 39.1 & -140.9 & \pm 13.9 \\
\hline \multirow[t]{4}{*}{128} & $88 \mathrm{a}$ & 16.4 & \pm 35.2 & -164.7 & \pm 16.8 \\
\hline & $161 \mathrm{a}$ & 28.8 & \pm 27.9 & -161.2 & \pm 16.9 \\
\hline & $37 d$ & -3.5 & \pm 26.5 & -210.4 & \pm 16.1 \\
\hline & $110 \mathrm{~d}$ & 6.7 & \pm 33.3 & -208.7 & \pm 18.8 \\
\hline \multirow[t]{4}{*}{141} & $88 \mathrm{a}$ & 19.2 & \pm 26.3 & -123.6 & \pm 15.8 \\
\hline & $161 \mathrm{a}$ & -0.6 & \pm 33.7 & -125.3 & \pm 19.0 \\
\hline & $37 d$ & -23.7 & \pm 25.7 & -188.0 & \pm 14.0 \\
\hline & $110 \mathrm{~d}$ & 5.6 & \pm 30.1 & -183.8 & \pm 17.2 \\
\hline \multirow[t]{4}{*}{148} & $88 \mathrm{a}$ & 16.1 & \pm 20.8 & -145.2 & \pm 17.3 \\
\hline & $161 \mathrm{a}$ & 29.7 & \pm 37.0 & -137.2 & \pm 17.9 \\
\hline & $37 d$ & 20.3 & \pm 24.1 & -151.2 & \pm 12.6 \\
\hline & $110 \mathrm{~d}$ & 8.5 & \pm 38.4 & -151.9 & \pm 12.2 \\
\hline
\end{tabular}

between ascending (negative $\Delta \alpha$ ) and descending (positive $\Delta \alpha)$ tracks, which is highest for transponder $141(>0.5 \mathrm{~m})$ and smallest for transponder $148(<0.1 \mathrm{~m})$. Although [1] report an incidence angle dependence of the transponder's internal range delay, our results could not confirm this. It is interesting to note the completely different range delay behavior between units 141 and 148, despite that these are separated only $46.5 \mathrm{~m}$. For standard deviations of the range coordinate differences, even if the uncertainties of GNSS measurements, orbit state vectors, and atmospheric signal delay corrections are considered, we still reach at least a factor 2 worse results. The average azimuth coordinate differences are all within the confidence interval of their standard deviations. For azimuth standard deviations, we reach the limit dictated by the SCR (CRB) and the azimuth resolution $(\sim 22 \mathrm{~m})$. More optimistic values are likely the result of the biased SCR estimate, see Sec. IV-A.

\section{DisCUSSION AND CONCLUSIONS}

From the experimental results with four compact transponders manufactured by [5], installed at two different test sites, we conclude that they have an average RCS of $40-45 \mathrm{dBm}^{2}$, which is comparable to a triangular trihedral corner reflector with a leg length of $2.0 \mathrm{~m}$.

An antenna misalignment by 12 and 3 degrees in elevation and azimuth angles, respectively (extreme values for Sentinel-1 over European latitudes), yields an RCS attenuation of up to $3 \mathrm{~dB}$. While this attenuation is rather modest, by modifying the default antenna alignment for the site-specific viewing geometry this attenuation can be further reduced. The temporal standard deviation of the transponders' RCS is up to $0.7 \mathrm{~dB}$, which is more than two times the standard deviation observed for a corner reflector of equivalent RCS, considering the $0.25 \mathrm{~dB}$ radiometric stability of the Sentinel-1 SLC measurements [32]. For some transponder units, and for sites with temperatures exceeding $20{ }^{\circ} \mathrm{C}$, the RCS variability is correlated with temperature variations. We observed this only for ascending orbits on only one test site. As the RCS directly influences the SCR, which is often used as a proxy for the precision of the phase, we find that this approach yields a too optimistic precision estimate. The normalized amplitude dispersion gives a more realistic estimate of the phase precision.

Regarding the constant internal electronic delays, we find delays varying between 1.2 and $2.1 \mathrm{~m}$. These are unit-specific and differ for ascending/descending antennas, but could not 

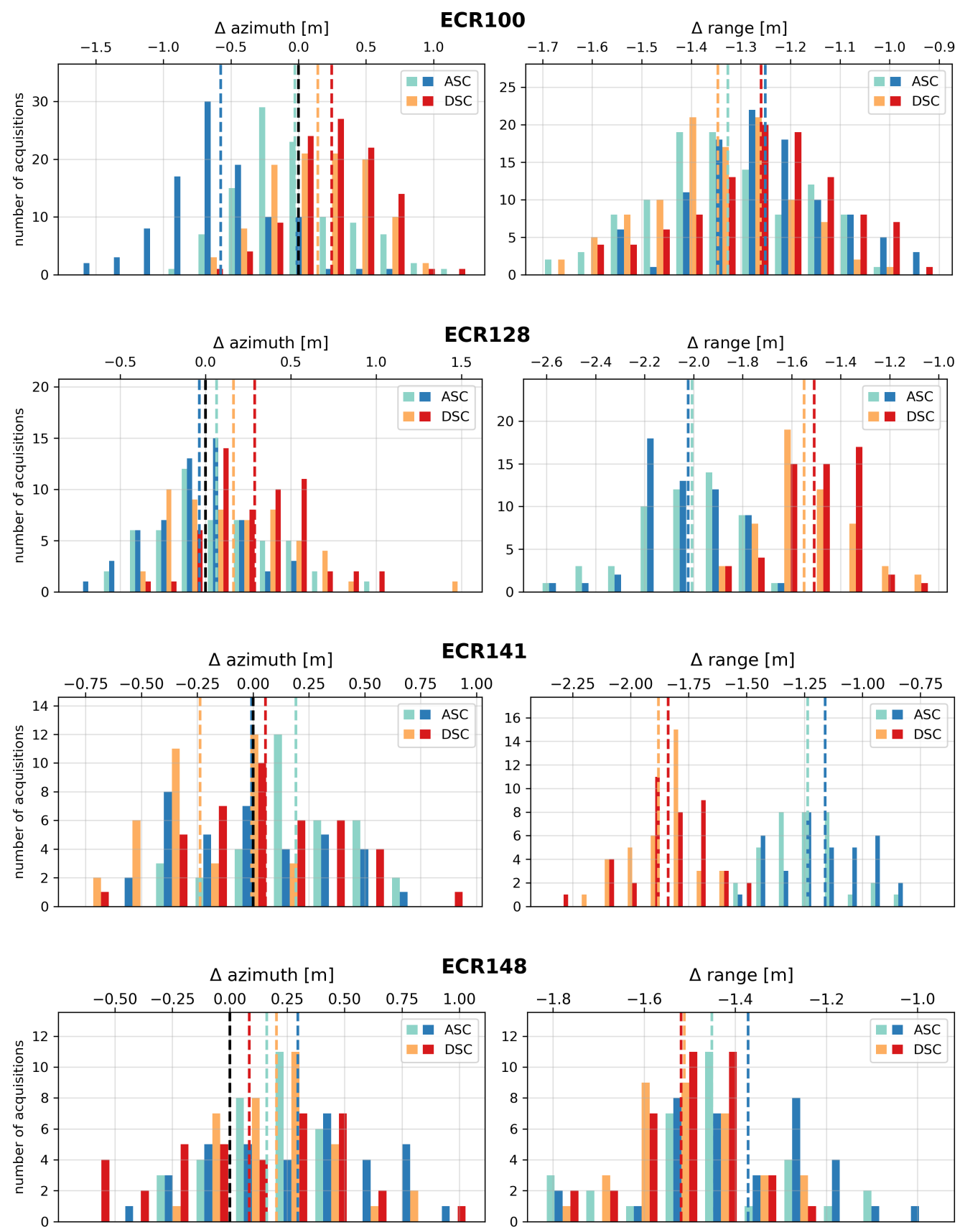

Fig. 16. Absolute Positioning Errors (APE) of the transponders from Sentinel-1 tracks

be proven to be dependent on incidence angle or the azimuth of the zero-Doppler plane. Thus, for absolute centimeterlevel geodetic positioning purposes, the transponders would require individual calibration models, similar as applied for geodetic GNSS antennas. The variable part of the absolute SAR positioning, in azimuth and range, is found to have a precision of $39.1 \mathrm{~cm}$ and $16.2 \mathrm{~cm}$, respectively.

Regarding the precision of the double-difference interferometric phase, relative to a passive reference reflector, we observe a phase standard deviation varying between 0.5 and $1.2 \mathrm{~mm}$, which implies a single-epoch undifferenced standard deviation of the transponder phase of 0.3 to $0.8 \mathrm{~mm}$.

Yet, we observe the phase to be significantly correlated with environmental temperature variations, showing variations within a range of $6 \mathrm{~mm}$. These can be modelled using a simple scaling factor, that needs to be computed specific per transponder unit.

Estimating this temperature-dependent scaling factor, i.e., removing the seasonal variability, yields an observed InSAR phase standard deviation of $0.5-0.7 \mathrm{~mm}$ in the LOS direction.

Regarding a potential phase drift, giving the maximum time interval of 21 months analyzed in this study, we find that if apparent at all, it is less than $1 \mathrm{~mm} / \mathrm{y}$. This is especially important for long-term InSAR reliability.

Finally, snow or ice cover on the transponder radome may cause undesired phase spikes with larger magnitudes than the 


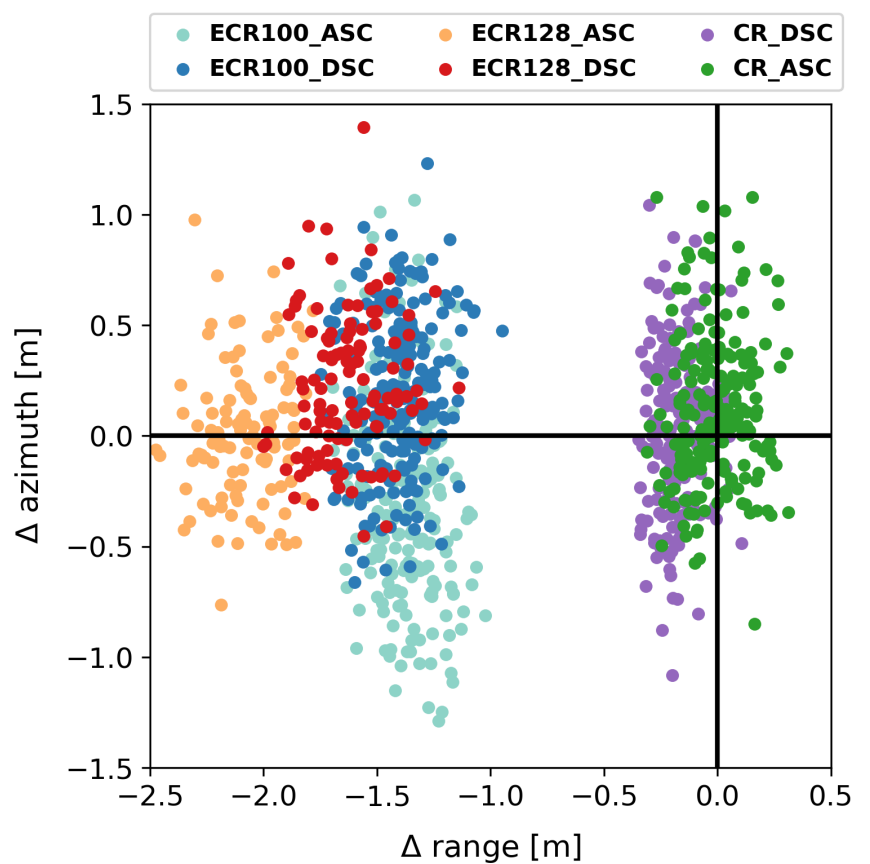

Fig. 17. Absolute Positioning Errors (APE) of the corner reflectors (CRAS/CRDS) and the transponders 100/128 at the WASS test site, using Sentinel-1 data.

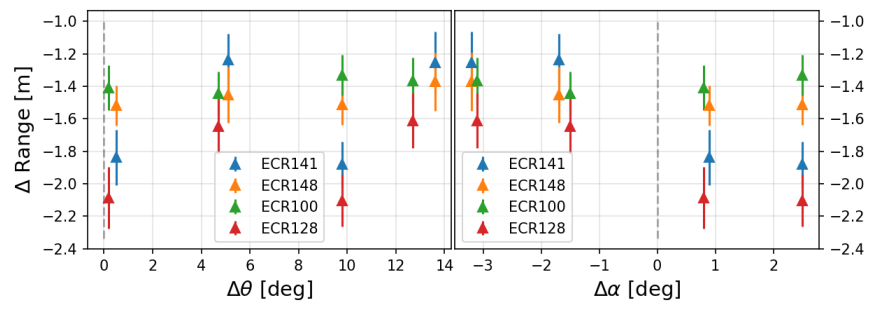

Fig. 18. Internal range delay versus antennas misalignment in elevation $(\Delta \theta)$ and azimuth $(\Delta \alpha)$ angles. Error-bars are 2.5 sigma.

phase accuracy.

In general, based on our analysis of amplitude and phase, we observe that transponder unit cannot be regarded as being equal. In fact different units are specific in terms of their radiometric, geometric, and phase stability. This supports the suggestion of performing unit-specific calibrations, both by the manufacturer and considering site-specific conditions.

\section{Practical Recommendations}

The decision whether to deploy transponders is very dependent on the specific case study. Yet, there are a few general considerations that can be recommended for each application. First, estimating the clutter at the location of preferred deployment is strongly recommended. The clutter power should be preferably less than $4 \mathrm{~dB}$, to obtain valuable estimates of phase, e.g., with a standard deviation of better than $2 \mathrm{~mm}$, and a distinct amplitude response. Second, when transponder units are ordered, the antenna orientation needs to be optimized for the specific geographic location of deployment. Note that this is not only latitude dependent, but it can also be optimized for the specific satellite orbits of interest. For example, for applications that require more (or less) sensitivity to vertical or horizontal displacement components, this is a parameter that can be optimized. Third, the transponders ideally need to include a calibration report with specific information on the constant and temperature-dependent internal delays. Alternatively, an on-site calibration campaign may be required, where we recommend to compute baselines with permanently installed corner reflectors of sufficient size and with a wellknown temporal behavior. Calibration activities containing two transponder units may not be sensitive to correlated signals, such as temperature variability. The duration of the calibration depends on the specific application. Several crosstrack acquisitions are already sufficient to obtain a reasonable estimate of the RCS and the internal delay.

For further research, we recommend extending experiments using longer Sentinel-1 and Radarsat-2 SAR time series to further improve robust estimates on the InSAR phase stability, especially on the possible secular drift.

Finally, we strongly support international activities in permanent deployment of transponders, mechanically coupled to GNSS antenna infrastructure and to tide gauges.

\section{REFERENCES}

[1] T. Gruber, J. Ågren, D. Angermann, A. Ellmann, A. Engfeldt, C. Gisinger, L. Jaworski, S. Marila, J. Nastula, F. Nilfouroushan, X. Oikonomidou, M. Poutanen, T. Saari, M. Schlaak, A. Światek, S. Varbla, and R. Zdunek, "Geodetic SAR for Height System Unification and Sea Level Research-Observation Concept and Preliminary Results in the Baltic Sea," Remote Sens., vol. 12, no. 22, 2020.

[2] C. Gisinger, M. Eineder, R. Brcic, U. Balss, T. Gruber, X. Oikonomidou, and M. Heinze, "First Experiences with Active C-Band Radar Reflectors and Sentinel-1," in IGARSS 2020 - 2020 IEEE International Geoscience and Remote Sensing Symposium, 2020, pp. 1165-1168.

[3] P. Mahapatra, S. Samiei-Esfahany, H. van der Marel, and R. Hanssen, "On the Use of Transponders as Coherent Radar Targets for SAR Interferometry," IEEE Trans. Geosci. Remote Sens., vol. 52, no. 3, pp. 1869-1878, March 2014.

[4] P. Mahapatra, H. van der Marel, F. van Leijen, S. Samiei Esfahany, R. Klees, and R. Hanssen, "InSAR datum connection using GNSSaugmented radar transponders," J. Geodesy, Jun. 2017.

[5] Metasensing, "Metasensing bv: Radar solutions - electronic corner reflector - c band (ecr-c)," https://www.geomatics.metasensing.com/ecrc, 2021.

[6] D. R. Brunfeldt and F. T. Ulaby, "Active Reflector for Radar Calibration," IEEE Trans. Geosci. Remote Sens., vol. GE-22, no. 2, pp. 165-169, 1984.

[7] A. Freeman, Y. Shen, and C. L. Werner, "Polarimetric SAR calibration experiment using active radar calibrators," IEEE Trans. Geosci. Remote Sens., vol. 28, no. 2, pp. 224-240, 1990.

[8] IERS, "International earth rotation and reference systems service," https://www.iers.org/, 2021.

[9] GKU Slovakia, "Geodetic and Cartographic Institute in Bratislava, Slovakia," https://www.geoportal.sk/sk/udaje/ortofotomozaika/, 2021.

[10] R. Hanssen, "A radar retroreflector device and a method of preparing a radar retroreflector device," Jun. 21 2017, international Patent WO2018236215A1. [Online]. Available: https://patents.google.com/patent/WO2018236215A1/en

[11] R. Czikhardt, H. van der Marel, and J. Papco, "GECORIS: An OpenSource Toolbox for Analyzing Time Series of Corner Reflectors in InSAR Geodesy," Remote Sens., vol. 13, no. 5, 2021.

[12] U. Balss et al., "Survey Protocol for Geometric SAR Sensor Analysis," German Aerospace Center (DLR), Technical University of Munich (TUM), Remote Sensing Laboratories - University of Zurich (RSL), Tech. Rep., Apr. 2018.

[13] U. Balss, C. Gisinger, and M. Eineder, "Measurements on the absolute 2-D and 3-D localization accuracy of TerraSAR-X," Remote Sens., vol. 10, no. 4, p. 656, 2018. [Online]. Available: https://doi.org/10.3390/rs10040656 
[14] C. Gisinger, A. Schubert, H. Breit, M. Garthwaite, U. Balss, M. Willberg, D. Small, M. Eineder, and N. Miranda, "In-Depth Verification of Sentinel-1 and TerraSAR-X Geolocation Accuracy Using the Australian Corner Reflector Array," IEEE Trans. Geosci. Remote Sens., vol. 59, no. 2, pp. 1154-1181, Feb. 2021.

[15] A. Gray, P. Vachon, C. Livingstone, and T. Lukowski, "Synthetic aperture radar calibration using reference reflectors," IEEE Trans. Geosci. Remote Sens., vol. 28, no. 3, pp. 374-383, Mar. 1990.

[16] A. Freeman, "SAR calibration: An overview," IEEE Trans. Geosci. Remote Sens., vol. 30, no. 6, pp. 1107-1121, Jun. 1992.

[17] N. Miranda and P. J. Meadows, "Radiometric Calibration of S-1 Level-1 Products Generated by the S-1 IPF," European Space Agency (ESA), Tech. Rep., May 2015.

[18] R. Piantanida, N. Miranda, and G. Hajduch, "Thermal Denoising of Products Generated by the S-1 IPF," MPC-S1, Tech. Rep., Nov. 2017.

19] R. Czikhardt, H. van der Marel, F. J. van Leijen, and R. F. Hanssen, "Estimating signal-to-clutter ratio of InSAR corner reflectors from SAR time series," IEEE Geosci. Remote Sens. Lett., vol. PP(99), 2021.

[20] C. Leys, C. Ley, O. Klein, P. Bernard, and L. Licata, "Detecting outliers: Do not use standard deviation around the mean, use absolute deviation around the median," J. Exp. Soc. Psychol., vol. 49, no. 4, pp. 764 - 766, 2013.

[21] P. Dheenathayalan, M. C. Cuenca, P. Hoogeboom, and R. F. Hanssen, "Small reflectors for ground motion monitoring with InSAR," IEEE Trans. Geosci. Remote Sens., vol. 55, no. 12, pp. 6703-6712, Dec. 2017.

[22] R. F. Hanssen, Radar interferometry: data interpretation and error analysis. Springer, 2001, vol. 2.

[23] G. Luzi, P. F. Espín-López, F. Mira Pérez, O. Monserrat, and M. Crosetto, "A Low-Cost Active Reflector for Interferometric Monitoring Based on Sentinel-1 SAR Images," Sensors, vol. 21, no. 6, 2021.

[24] S. Raab, B. J. Doering, D. Rudolf, J. Reimann, and M. Schwerdt, "Analysis of an improved temperature management concept for SAR system calibration transponders," in Proceedings of EUSAR 2016: 11th European Conference on Synthetic Aperture Radar, 2016, pp. 1-6.

[25] K.-R. Koch, Parameter Estimation and Hypothesis Testing in Linear Models, 2nd ed. New York: Springer-Verlag, 1999.

[26] A. Ferretti, C. Prati, and F. Rocca, "Permanent Scatterers in SAR Interferometry," IEEE Trans. Geosci. Remote Sens., vol. 39, no. 1, pp. 8-20, Jan. 2001.

[27] I. G. Cumming and F. H. Wong, Digital processing of Synthetic Aperture Radar data: : Algorithms and Implementation, ser. 1. The address: Artech House, 1 2005, vol. 1.

[28] H. Hersbach and D. Dee, "Era5 reanalysis is in production, ecmwf newsletter 147," pp. 5-6, 2016. [Online]. Available: https://www.ecmwf.int/en/newsletter/147/news/era5reanalysis-production

[29] IGS, "International gnss service," http://www.igs.org/, 2021.

[30] R. Bamler and M. Eineder, "Accuracy of differential shift estimation by correlation and split-bandwidth interferometry for wideband and deltak SAR systems," IEEE Geosci. Remote Sens. Lett., vol. 2, no. 2, pp. 151-155, Feb. 2005.

[31] H. Peter, A. Jäggi, J. Fernández, D. Escobar, F. Ayuga, D. Arnold, M. Wermuth, S. Hackel, M. Otten, W. Simons, P. Visser, U. Hugentobler, and P. Féménias, "Sentinel-1A - First precise orbit determination results," Advances in Space Research, vol. 60, no. 5, pp. 879 - 892, 2017.

[32] CLS, "Sentinel-1A N-Cyclic Performance Report - 2020-07," Collecte Localisation Satellites (CLS), Ramonville Saint-Agne, France, Tech. Rep., Jul. 2020

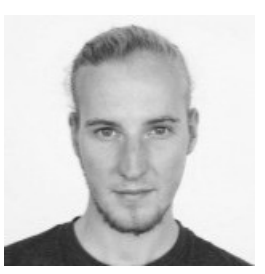

Richard Czikhardt received the M.Sc. degree in geodesy and cartography in 2017 and is currently pursuing a Ph.D. degree with the Department of Theoretical Geodesy and Geoinformatics, Slovak University of Technology, Bratislava, Slovakia. His primary research is on Interferometric Synthetic Aperture Radar (InSAR) geodesy, focusing on advanced InSAR processing techniques, quality control, and geodetic integration using artificial radar reflectors. In 2019, he served as a research intern at the Department of Geoscience and Remote Sensing,

Delft University of Technology. He has practical experience with InSAR software development, time series analysis, image processing, satellite and ground-based geodetic techniques and geographic information systems.

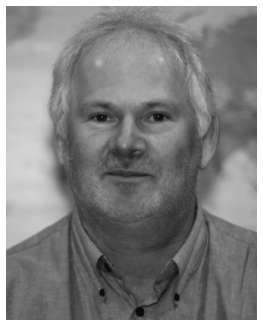

Hans van der Marel received the M.Sc. degree in geodetic engineering and the Ph.D. (cum laude) degree from the Delft University of Technology, Delft, The Netherlands, in 1983 and 1988, respectively. He is an Assistant Professor with the Department of Geoscience and Remote Sensing, Delft University of Technology, Delft, The Netherlands. From September 1983 until July 1987, he was a Research Fellow with the Netherlands Organisation for Scientific Research and worked on the scientific data reduction for the astronomical satellite Hipparcos. From 1987 until 1989, he was a Research Fellow with the Netherlands Academy of Sciences. In 1989, he became an Assistant Professor with the Delft University of Technology in Global Navigation Satellite Systems (GNSS), with a specific interest in high-precision scientific and meteorological applications of GNSS

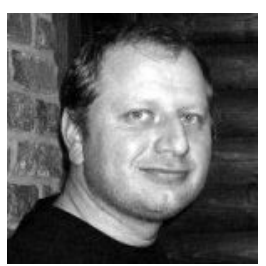

Juraj Papco received the Ph.D. degree in geodesy and cartography from Slovak University of Technology, Bratislava, Slovakia, in 2010. Since 2004, he has been a Researcher and Lecturer in global geodesy and remote sensing with the Slovak University of Technology. As the principal investigator, he has experience in managing several satellite-InSARrelated projects, unique for Slovakia territory. His main research interests include satellite geodesy, GNSS, remote sensing, SAR and InSAR, deformaand land surveying.

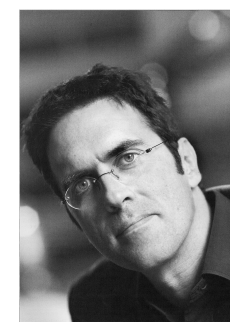

Ramon F. Hanssen (M'04-SM'15) received the M.Sc. degree in geodetic engineering and the Ph.D. (cum laude) degree in geodetic engineering from Delft University of Technology, Delft, The Netherlands, in 1993 and 2001, respectively. $\mathrm{He}$ was with the International Institute for Aerospace Survey and Earth Science, Stuttgart University, the German Aerospace Center (DLR), Stanford University (Fulbright Fellow), and the Scripps Institution of Oceanography where he worked on microwave remote sensing, radar interferometry, signal processing, and geophysical application development. Since 2008, he has been Antoni van Leeuwenhoek Professor in geodesy and satellite earth observation at Delft University of Technology. He is the author of a textbook on radar interferometry. 